\title{
Environmentally Friendly Formulations of Trifluralin Based on Alginate Modified Starch
}

\author{
Ikenna Onyido ${ }^{1}$, Rufus Sha'Ato ${ }^{2}$, Lami A. Nnamonu ${ }^{2 *}$ \\ ${ }^{1}$ Department of Chemistry, Nnamdi Azikiwe University, Awka, Nigeria; ${ }^{2}$ Department of Chemistry, University of Agriculture, Ma- \\ kurdi, Nigeria. \\ Email: *lami.nnamonu@gmail.com
}

Received June $17^{\text {th }}, 2012$; revised July $16^{\text {th }}, 2012$; accepted August $10^{\text {th }}, 2012$

\begin{abstract}
In line with global efforts towards sustainable agriculture, the use of starch modified with alginate in the preparation of slow release formulations of the herbicide trifluralin was investigated. Trifluralin was encapsulated in starch-alginate beads, and the resulting slow release formulations (SRFs) characterized using scanning electron microscopy (SEM) and Fourier Transform infrared (FTIR) spectroscopy. Herbicide release from the SRFs was studied in water and compared to release of technical grade trifluralin. Three sets of formulations were made by extrusion into $0.25 \mathrm{M}$ calcium chloride solution: starch/alginate (SSTRF), amylose starch/alginate (ASSTRF) and amylose starch/alginate/groundnut oil (ASTRGNO) beads, and the fourth was from gelatinized starch at $75^{\circ} \mathrm{C}$ (SSTRF2). The results showed highly porous spherical beads, the amylose/alginate beads bigger and less porous than the starch/alginate beads with diameters of $2.79 \pm$ 0.01 and $2.37 \pm 0.01 \mathrm{~mm}$; porosity of $54.67 \pm 0.2$ and $60.59 \% \pm 0.2 \%$ and swelling of $54.09 \pm 0.2$ and $61.22 \% \pm 0.2 \%$, respectively. All sets of beads exhibited reduced crystallinity of trifluralin. FTIR revealed a shift to lower wavelength of the carbonyl stretching vibrations from 1750 to $1725 \mathrm{~cm}^{-1}$ and a reduction in intensity of the carboxylate peaks of alginate, suggesting interactions between the formulation components that make for good slow release. $96 \%$ of technical grade trifluralin (TGTRF) was released into a $50: 50 \mathrm{pH} 6.5 \mathrm{Buffer} /$ Methanol aqueous medium in $24 \mathrm{hrs}$. However, for the starch/TRF formulation, SSTRF, only 9.33\% herbicide was released after $24 \mathrm{hrs}$ and $34.94 \%$ after $672 \mathrm{hrs} \mathrm{(28} \mathrm{days).}$ The amylose starch/TRF formulation released $13.61 \%$ herbicide in $24 \mathrm{hrs}$ and $46.95 \%$ in $672 \mathrm{hrs}$, a $12 \%$ increase in release of TRF over the starch formulation. Encapsulation in starch produced $65 \%$ slow release of TRF and gelatinization achieved $84 \%$ retardation. Use of amylose starch as matrix caused $53.15 \%$ delay and addition of groundnut oil resulted in $80.87 \%$ retardation of TRF release. Encapsulation of TRF in starch/alginate beads is a veritable way of reducing negative environmental effects.
\end{abstract}

Keywords: Alginate; Groundnut Oil; Starch; Slow Release; Trifluralin

\section{Introduction}

Slow release formulation (SRF) of pesticides improves their delivery by optimizing their activity profile while limiting contact with the environment. In this setting, the amount of pesticide immediately available for undesirable losses is minimized through its application as a material adsorbed on a matrix or carrier. Generally, the advantages of slow release formulations are satisfactory effect at a constant active ingredient level for a longer period of time (residual effect), smaller dosage (less active ingredient is needed to maintain effective biological activity) by elimination of repeat applications and therefore reduced cost (safety and resource-saving), and longer application interval (labour-saving). Other advantages include reduced risk of mammalian toxicity, re-

${ }^{*}$ Corresponding author. duced phytotoxicity, decreased leaching/evaporative losses [1], decreased environmental degradation, reduced contamination and pollution of the environment. There is also ease of handling, masking of odours [2], minimization of residues on foodstuff and decreased dermal toxicity [3].

Trifluralin ( $\alpha, \alpha, \alpha$-trifluoro-2,6-dinitro- $N, N$-p-toluidine) is a selective pre-emergence dinitroaniline herbicide widely used in the control of annual grasses and broadleaf weeds in horticultural and agricultural crops [4]. It is registered in more than fifty countries for use on more than eighty crops [5]. Trifluralin is a persistent soil contaminant (due to its strong adsorption to soil particles). In spite of its low water solubility, it has been reported as a surface water pollutant [6]. Even though it has low leachability, trifluralin has a very high bio-concentration factor. It is photo labile, a serious drawback for field ap- 
plication since the quantity and frequency of application must be increased to ensure its effectiveness. These factors make trifluralin (TRF) a good candidate for slow release formulation.

Alginate gels are used as matrices for SRF in agricultural applications because of their biodegradability and the ease of incorporation of active ingredients using an aqueous system at ambient temperatures. The leaching of pesticides during the preparation of alginate beads has been improved by synthesizing bi-polymeric beads of alginate with other natural polysaccharides. Alginateclay complexes have been used for various pesticides: diquat bromide [7], 2,6-dichlorobenzonitrile [8], carbofuran [9], thiobencarb [10], metribuzin and alachlor $[11,12]$ and diuron [13]. Starch has been incorporated into alginateclay formulations of thiram $[14,15]$.

Sprayable controlled release (CR) formulations of TRF have been made with starch. One such formulation using starch xanthide was made by first forming starch xanthate, followed by dispersal of the trifluralin in the xanthate and coagulating the dispersion by oxidation to starch xanthide [16]. Spray-dried aqueous dispersions of starch [17] and polypropylene pellets [18] have also been reported and the pellets were evaluated for their herbicidal efficacy and release in water.

We hereby report the direct, simple and effective encapsulation of TRF in alginate reinforced starch to produce solid slow release beads, and characterization of same. The method cuts out multi-step conversions and does not involve use of sophisticated equipment. The use of alginate helps bead formation and strengthens the starch matrix. Scanning electron microscopy (SEM) was used to determine bead shape, diameter, overall morphology and distribution of the trifluralin herbicide in the formulation, and information on intermolecular interactions was obtained using Fourier Transform infrared (FTIR) spectroscopy. Release of herbicide was studied under laboratory conditions in methanol/pH $6.5 \mathrm{KH}_{2} \mathrm{PO}_{4}$ buffer.

\section{Experimental Procedure}

\subsection{Materials}

Corn starch amylopectin, corn starch amylose (both practical grade), trifluralin, calcium chloride dihydrate and sodium alginate were obtained from Sigma Aldrich UK and used as received. Sodium hexametaphosphate was purchased from VWR Prolabo (BDH) International N/ America and Europe. Peristaltic Pump tubes (blackwhite, 3 - $16 \mathrm{~mm}$ PVC) were purchased from Anachem, UK. Glacial acetic and sodium hydroxide are the other materials used. High purity water used all through this work was obtained from a purification unit by Millipore ${ }^{\circledR}$ Corporation.
Starch as used in this work refers to a 20:80 mixture of pure corn amylose: amylopectin starch, whereas amylose starch is $100 \%$ corn amylose without amylopectin.

\subsection{Methods}

\subsubsection{SR Beads Formation}

Three types of SR gel beads were prepared by extrusion into calcium chloride solution: one set with starch and alginate was code named SSTRF, the second with amylose starch and alginate was code named ASSTRF and the third (ASTRGNO) had groundnut oil (3\%) added to the amylose starch alginate mixture during stirring. The fourth formulation (SSTRF2) was formed by gelatinization of the starch slurry at $75^{\circ} \mathrm{C}$. An aqueous dispersion containing $3 \%(w / w)$ of sodium alginate, $2 \%(w / w)$ of trifluralin and $15 \%(\mathrm{w} / \mathrm{w})$ starch (or amylose) was added drop wise by extrusion through a silicone tubing (internal diameter $3 \mathrm{~mm}$ ) with the aid of a peristaltic pump (Pharmacia LKB pump P-1), at a flow rate of 48 droplets $/ \mathrm{min}$, to a $200 \mathrm{ml}$ gelling solution of $0.25 \mathrm{M} \mathrm{CaCl}_{2} \cdot 2 \mathrm{H}_{2} \mathrm{O}$ [19]. The bi-polymeric beads formed immediately the slurry droplets hit the calcium chloride solution. The distance from the orifice to the surface of the gelling solution was $240 \mathrm{~mm}$ to allow good droplet penetration, the beads were allowed to set for 25 minutes, suction-filtered through a coarse frit Buchner funnel, washed twice with distilled water and air-dried. Blank beads were prepared in the same way but without herbicide.

\subsubsection{Swelling}

Swelling studies of the beads were conducted by the water evaporation method straight after separation from the gelling solution. A sample of the beads was blotted with Kimberly-Clark ${ }^{\circledR}$ professional medical wipes to remove excess water and weighed immediately in a weighing boat. The sample was air-dried in the fume cupboard and weighed until constant dry mass was attained, which took between 24 to $48 \mathrm{hrs}$. Percent equilibrium swelling of the beads was computed from mass changes.

\subsubsection{Porosity}

Porosity of beads was determined by the volume/density method. A $10 \mathrm{ml}$ measuring cylinder was weighed empty, beads poured in and the sides of the cylinder gently tapped until the beads were well packed. The total volume $\left(V_{t}\right)$ was noted and the cylinder and contents weighed. The volume occupied by the beads, $V_{b}$ was calculated using the density of the matrix $(\rho)$.

Pore volume and percent porosity were deduced from these.

$$
\text { Pore volume, } \begin{aligned}
\left(V_{p}\right)= & \text { Total volume }\left(V_{t}\right) \\
& - \text { Volume of beads }\left(V_{b}\right)
\end{aligned}
$$




$$
\% \text { Porosity }=\frac{\text { Pore volume }\left(V_{p}\right)}{\text { Total volume }\left(V_{t}\right)} \times 100
$$

Note: Density (g/ml) of matrices: Algin 1.73; Chitosan 0.6 - 0.8 (high density)

Diameter was an average of measurements taken with Vickers M17 Industrial microscope and the scanning electron microscope.

\subsubsection{Active Ingredient Loading}

Accurately weighed duplicate samples of two or three beads from each SR formulation was taken in $5 \mathrm{ml}$ methanol and totally disintegrated by placing in a sonicator for 30 - 45 minutes each in corked glass vials. These were crushed if necessary, left to stand for $24 \mathrm{hrs}$, diluted, filtered through a syringe filter $(0.2 \mu \mathrm{m})$ and analyzed for herbicide. Actual TRF loading (g/g) = Mass of TRF in sample formulation/ Mass of sample formulation. The values of TRF loading obtained were used to compute the encapsulation efficiency (e.e) of the SR formulations. Encapsulation efficiency, e.e. $(\%)=($ Actual loading/Theoretical loading) $\times 100$.

\subsubsection{Scanning Electron Microscopy}

The shape, external morphology and internal structure of the SR formulations were examined by scanning electron microscopy. SEM images (at different magnifications) of dry whole beads and their cross sections were captured on an FEI/PHILIPS XL 30 ESEM microscope after the samples were deposited on brass stubs (using double sided carbon tapes) and sputter coated with gold (20 nm) on an Edwards Pirani 501 Scan Coat Six sputter coater. The samples were exposed to accelerated voltage beam strength of $20.0 \mathrm{KV}$.

\subsubsection{Release Experiment}

The release of TRF from the beads was monitored by static immersion technique [20]. Accurately weighed quantities of dry SR beads (two replicates of each sample)

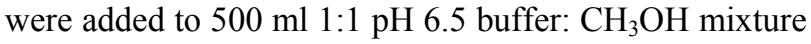
in corked $500 \mathrm{ml}$ borax bottles. The systems were manually agitated end-over-end thrice and left to stand. At specific time intervals, the bottles were shaken in the same way, allowed to settle for 2 minutes and $5 \mathrm{ml}$ aliquots were withdrawn, filtered and analyzed for herbicide by UV-visible spectrophotometry. Each aliquot withdrawn was replaced by $5 \mathrm{ml}$ of the buffer: $\mathrm{CH}_{3} \mathrm{OH}$ mixture to maintain sink conditions.

UV-Vis scan of Trifluralin samples gave two absorption peaks - a high intensity peak at $275 \mathrm{~nm}$ and another peak of smaller intensity at $390 \mathrm{~nm}$. Changes in the intensity of the lower wavelength peak were not commensurate with concentration of herbicide. However, the smaller peak at higher wavelength exhibited changes in intensity perfectly consistent with changes in herbicide concentration [21]. This peak was therefore used to quantify trifluralin in this work.

\section{Results and Discussion}

\subsection{Encapsulation}

It was not possible to form beads with plain starch paste. It was therefore necessary to modify starch with alginate to help bead formation and reduce leakage of encapsulated herbicide. The starch matrix also acquires higher mechanical strength with the alginate gel mass support The structure of starch is modified by cross linking with alginate via intermolecular hydrogen bonding (Figure 1).

Formulation characteristics are displayed in Table $\mathbf{1 .}$

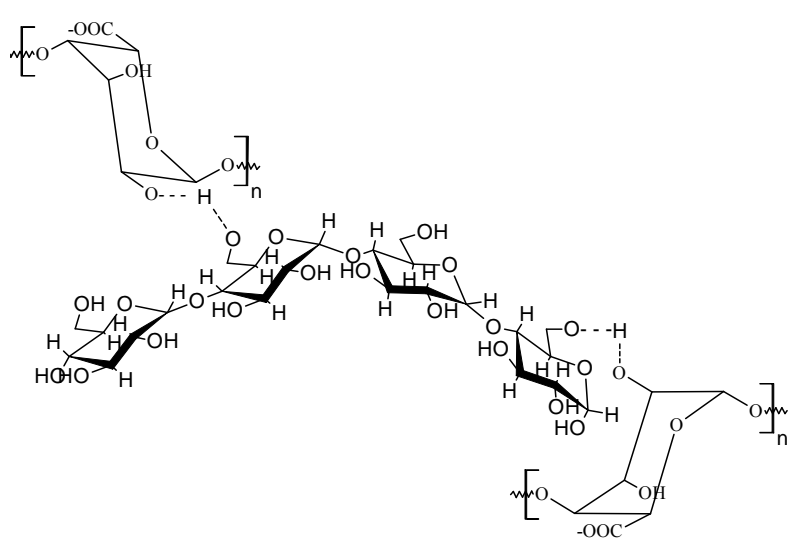

Figure 1. Starch-alginate cross linking interaction.

Table 1. Formulation characteristics.

\begin{tabular}{|c|c|c|c|c|c|}
\hline $\mathbf{S} / \mathbf{N}$ & Formulation property & SSTR & SSTRF2 & ASTR & ASTRGNO \\
\hline 1 & Herbicide loading (mg/g) & 7.70 & 0.90 & 20.00 & 13.40 \\
\hline 3 & Recovery of solids (\%) & 99.71 & 99.02 & 95.26 & 99.38 \\
\hline 4 & Diameter (mm) & 2.37 & NA & 2.79 & 2.53 \\
\hline 5 & Porosity (\%) & 60.59 & 32.49 & 54.67 & 51.04 \\
\hline 6 & Swelling (\%) & 61.22 & 31.73 & 54.09 & 50.99 \\
\hline
\end{tabular}


Active ingredient loading and encapsulation (or incorporation) efficiency are two important factors in the evaluation of the quality of formulations. High encapsulation efficiency, between $77.20 \%$ and $82.60 \%$, were obtained for all formulations (Table 1). Active ingredient loading was between 0.90 and $20.00 \mathrm{mg} / \mathrm{g}$. Loading was lowest for the gelatinized formulation for the obvious reason that some TRF was lost before the gelatinization temperature was attained. Gelatinization is therefore not recommended for making SR formulations of TRF but could be applied for higher melting pesticides. Recovery of solids was between $95 \%-100 \%$. Mean porosity estimates of the dry formulations were $\leq 62 \%$, the highest values being recorded for SSTR and lowest for SSTRF2. Diameter was from 2.37 to $2.79 \mathrm{~mm}$, the amylose beads larger than the starch beads.

\subsection{Scanning Electron Microscopy}

SEM images of whole beads and cross sections, at magnifications spanning $35 \times$ to $3500 \times$, are presented in Plates 1 and 2.
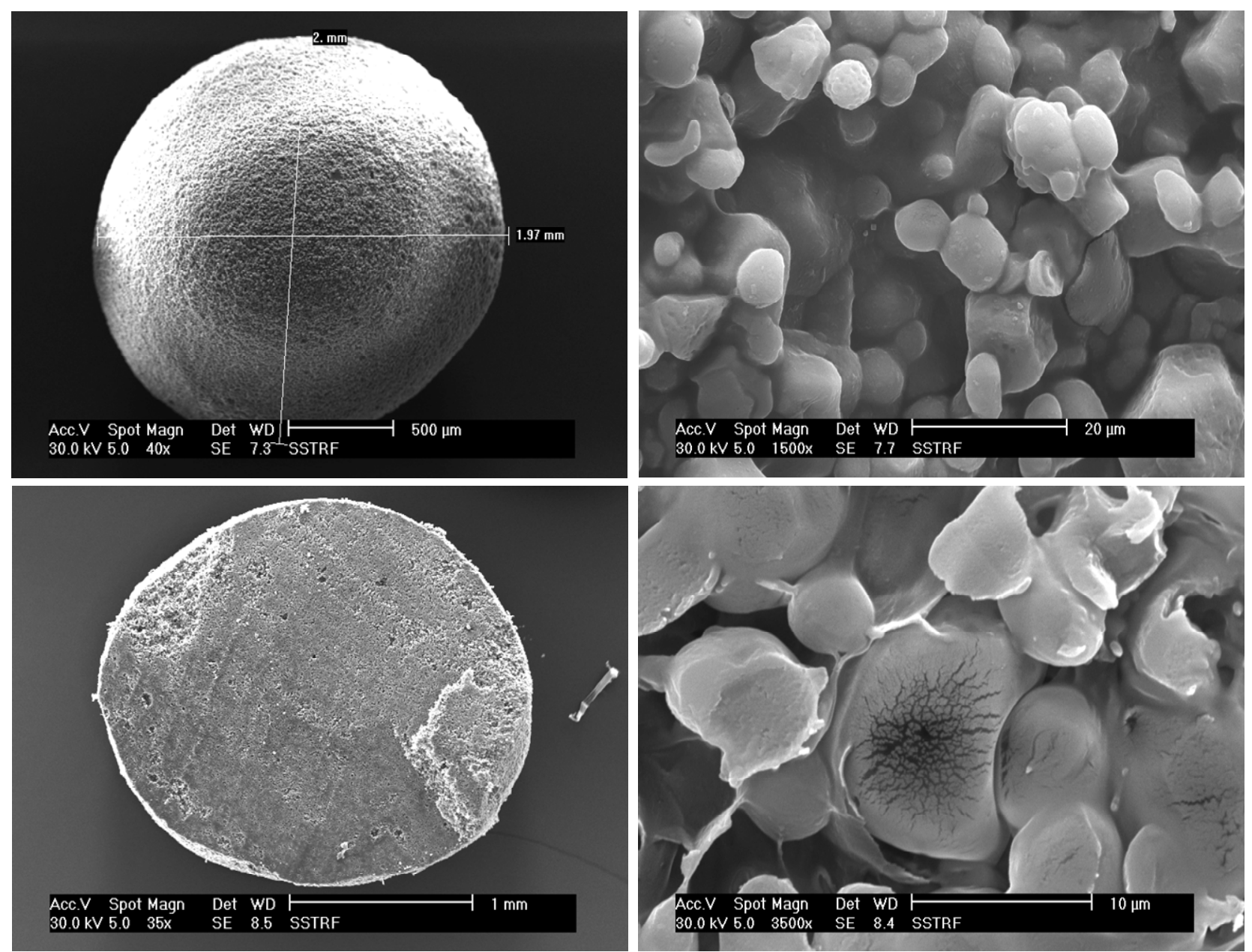

The starch formulation beads (Plate 1) have smooth surfaces with micro pores visible in the SEM micrographs of the beads. Higher magnification revealed typical micro-reticular structure with spherical primary particles of about $3 \mathrm{~mm}$. Also, there were interstices visible in the starch-TRF micrograph $(\times 1500$ magnification) which was confirmed in the cross-section at the bottom of the same plate. The corn amylose/trifluralin formulation (Plate 2) had similar external morphology but higher magnification $(\times 1500)$ applied to both samples reveals a less porous internal structure for amylose. The corn amylose beads were bigger than the starch beads.

\subsection{Fourier Transform Infrared Spectroscopy}

FTIR spectra (Spectrum 100 Fourier Transform IR Spectrophotometer) of the herbicide, herbicide incorporated formulation and the blank matrix formulation, are shown in Figures 2 and 3.

Cross linking of sodium alginate by $\mathrm{Ca}^{2+}$ was shown by a decrease in the wavenumber of the carbonyl peak from 1750 to $1725 \mathrm{~cm}^{-1}$, and a reduction in the intensity

Plate 1. Starch/TRF SR bead \& cross section. 

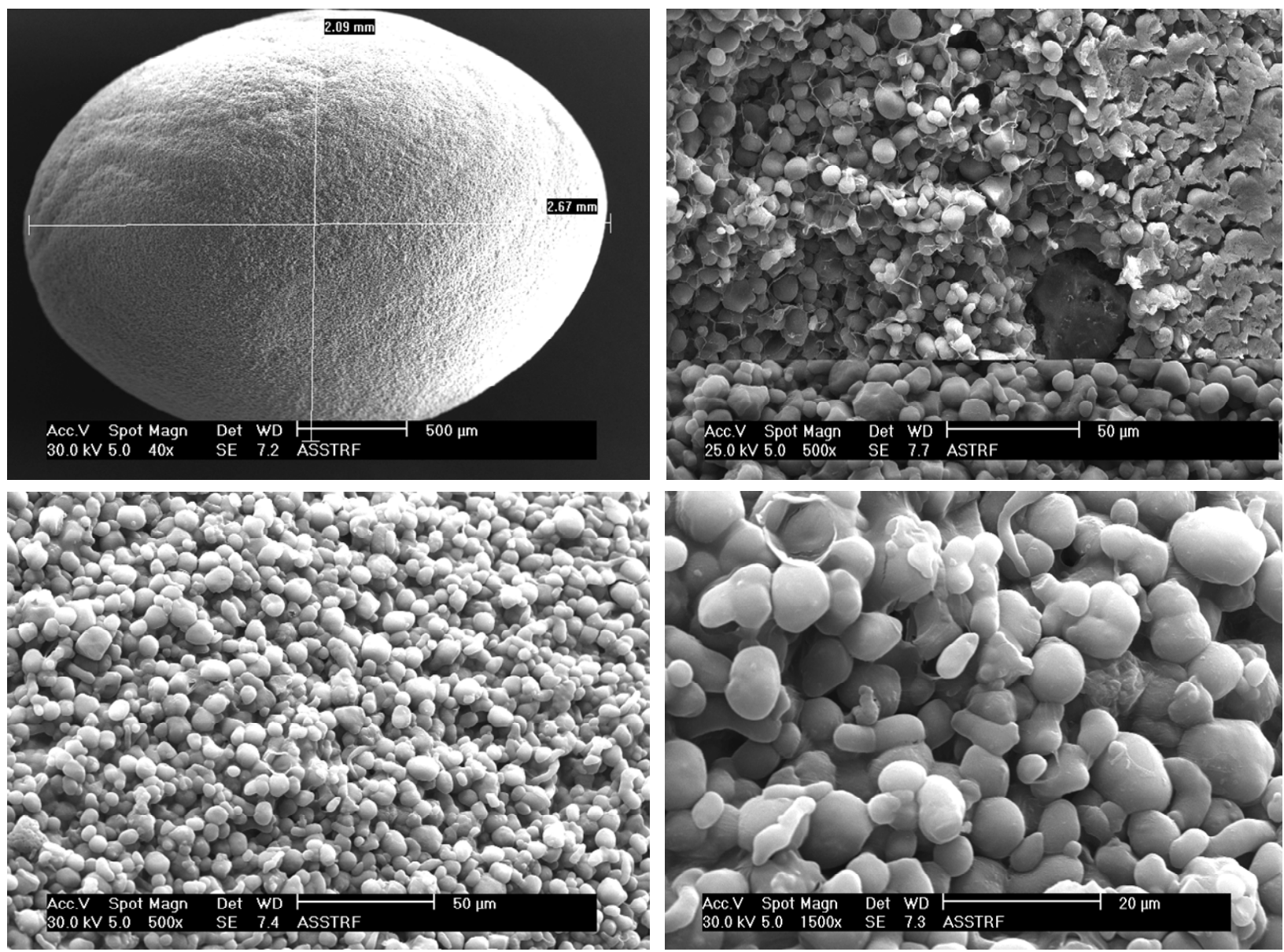

Plate 2. Corn amylose/TRF SR bead.

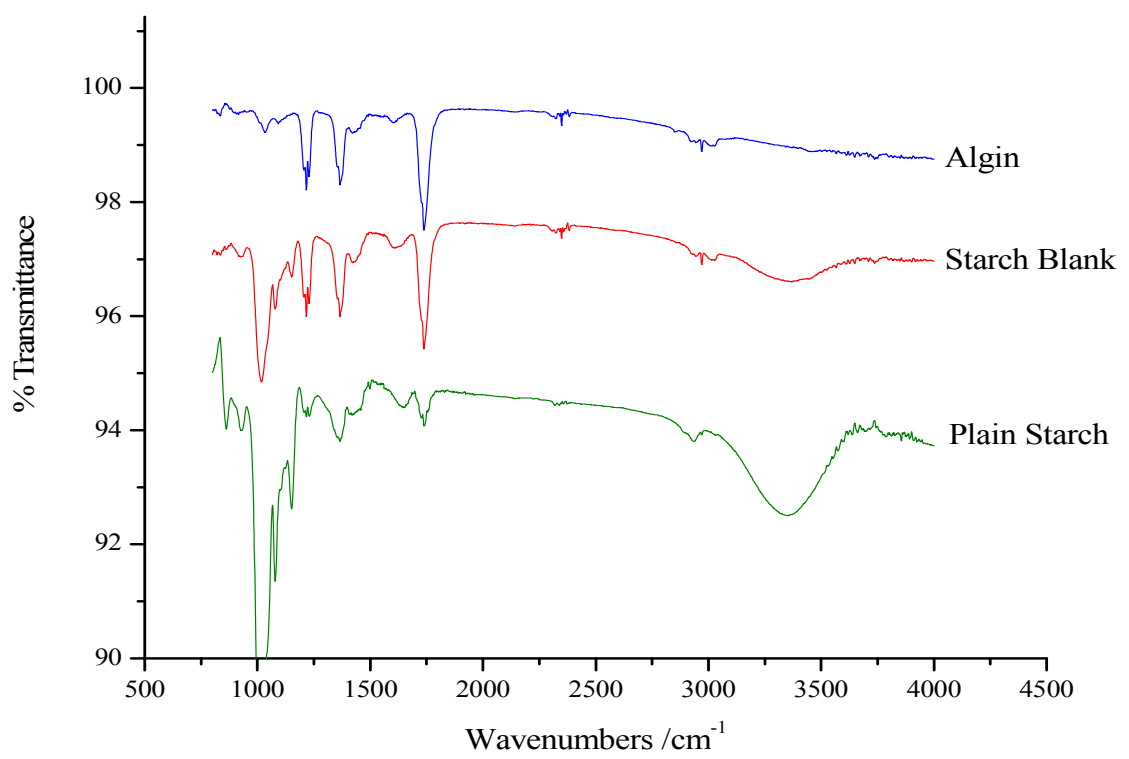

Figure 2. FTIR spectra of plain starch, blank formulation and alginate.

of peaks associated with the carboxylate groups. The -OH peak of calcium alginate had a higher wavenumber $\left(3435 \mathrm{~cm}^{-1}\right)$ than that of sodium alginate $\left(3410 \mathrm{~cm}^{-1}\right)$.
This was probably due to a negative effect on bond formation involving adjacent hydroxyl groups as a result of conformational changes of alginate after reacting with 


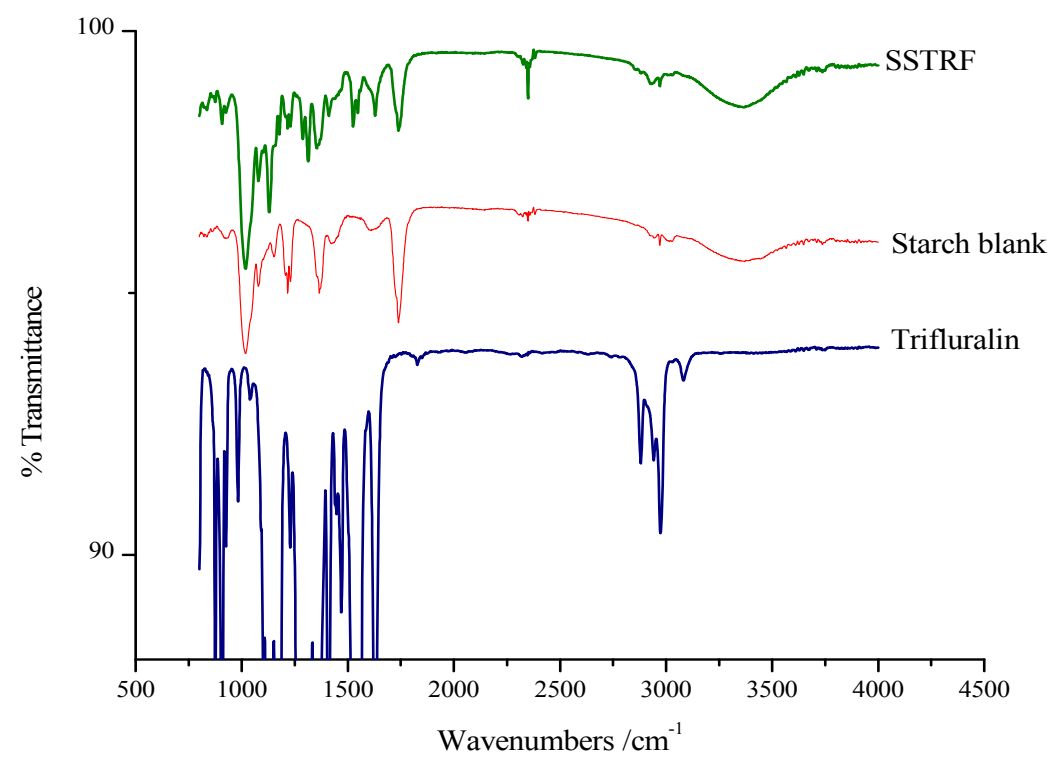

Figure 3. FTIR spectra of SSTR, blank formulation and trifluralin.

$\mathrm{Ca}^{2+}$. The shift of carbonyl $\mathrm{CO}$ stretching vibration to lower wave number implies that H-bonds may have also been formed between TRF and starch. The -OH groups on starch serve as proton donors for such $\mathrm{H}$ bonds.

\subsection{Release Profile}

Release profile of incorporated herbicides in SR formulations is a function of herbicide properties and matrix characteristics [15]. The formulations investigated in this work gave TRF release profiles that would be appropriate for herbicide delivery: an initial burst that could kill weeds present before planting of the crop (or at the time of application) followed by steady release during crop growth to prevent the emergence of competing weeds. Release profiles for all four formulations are shown in Figure 4.

Diffusion controls the release of herbicides from various alginate-based SR formulations into water. In this situation, the sorption capacity of the matrices used in entrapping the herbicides is the most influential factor. Pesticide release depends on two simultaneous rate processes: water migration into the beads and diffusion through continuously swelling beads [15]. Previous laboratory studies [22] have indicated that, on initial contact with water, atrazine is rapidly released from the starch matrix exterior and the starch granule swells. A balance between the process of migration of water into the beads and diffusion through the swollen beads explains the steady amount of TRF release attained after the initial burst in this work.

\subsection{Release Rates}

The amylose content of the starch, whether the starch is gelatinized or not, and the solubility of the active ingredient influence the SR properties of the final product. Considering that $100 \%$ technical grade TRF was released within the same period of time, encapsulation of TRF in starch reduced its release to $34.94 \%$ (Table 2).

Gelatinization induced a further reduction in amount released to $16.30 \%$. This is a total retardation of $84 \%$ compared to technical grade TRF. Use of amylose starch caused a $12 \%$ increase in release of TRF over the starch formulation (from $34.94 \%$ to $46.95 \%$ ), whereas addition of GNO to the amylose starch reduced the amount released from $46.95 \%$ to $19.13 \%$. This is an $81 \%$ slow release as compared to technical grade trifluralin.

This work reveals that corn amylose releases higher doses of trifluralin. This is not in agreement with the earlier report that the higher the amylose content of the starch, the lower the release rate of the active ingredients from the formulation since increasing amylose content confers higher gel-strength for the same starch concentration [23]. The observation in this study could be because the amylose beads were less porous and of larger diameter. Conversely, gelatinization slows down the release of trifluralin because the process further strengthens the gel.

Release rates recorded in this work are generally lower than those from other investigations of pesticide release from starch formulations. Atrazine-starch formulations were found to release $35 \%-60 \%$ of active ingredient in $48 \mathrm{hrs}$ depending on the degree of gelatinization and amylose content [24]. It was found that starch formulations of metolachlor released $94 \%-100 \%$ of the active ingredient in $21 \mathrm{hrs}$ while $41 \%$ - $49 \%$ of the active ingredient was released in the same period of time when alachlor was incorporated [25]. Starch formulations of 

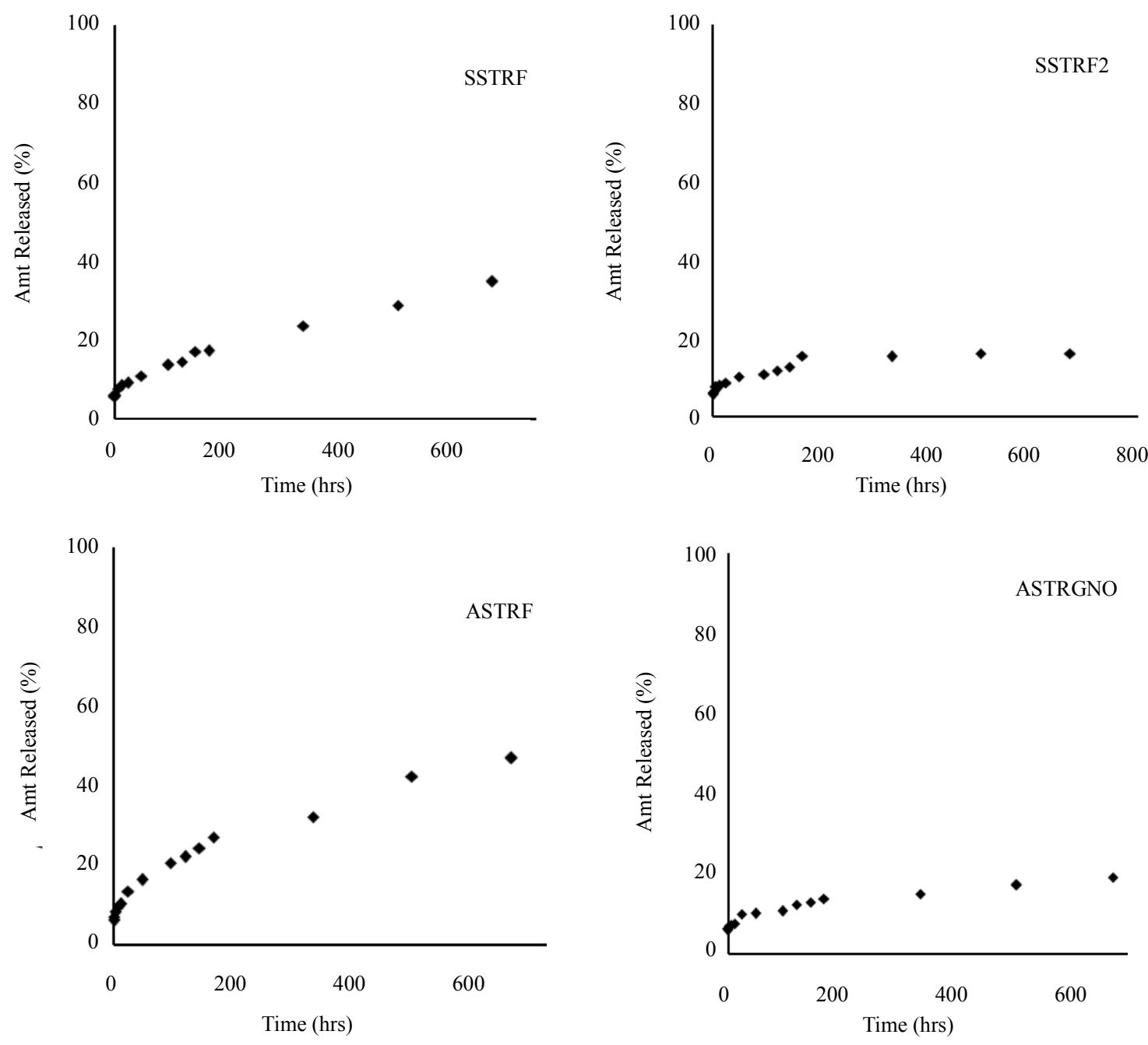

Figure 4. Release profile of TRF from starch formulation.

Table 2. Amount of TRF released from SRFs.

\begin{tabular}{cccc}
\hline $\mathbf{S} / \mathbf{N}$ & Sample code & \% released in $\mathbf{2 4} \mathbf{~ h r s}$ & \% released in $\mathbf{6 7 2} \mathbf{~ h r s ~}$ \\
\hline 1 & SSTRF & 9.33 & 34.94 \\
2 & SSTRF2 & 8.79 & 16.30 \\
3 & ASSTRF & 13.61 & 46.95 \\
4 & ASTRGNO & 9.80 & 19.13 \\
\hline
\end{tabular}

butylate, prepared by jet-cooking released $20 \%-50 \%$ of the active ingredient in $4 \mathrm{hrs}$ depending on temperature during release, and the amylose content of the starch [23]. The slower rates observed in this work are attributed to alginate modification of the starch matrix.

The groundnut oil provided a partitioning medium for the trifluralin within the starch-alginate gel mass, causing a further slowing down of release. Similar effect was reported where the addition of linseed oil to clay-alginate formulations of alachlor, atrazine and dicamba reduced the amount of alachlor released after $24 \mathrm{hrs}$ from $51 \%$ to $12 \%[26]$.

\section{Conclusion}

In a bid to decrease the environmental impact of pesticides, the use of starch combinations with alginate and groundnut oil for the preparation of slow release formulations of trifluralin was studied. The amylose content of the starch used for encapsulation and addition of groundnut oil affects the release of trifluralin from the SR for- 
mulations. Encapsulation of TRF in alginate modified starch achieved up to $84 \%$ slow release. Considering the outcry from farmers on the lack of substitute for trifluralin use on vegetables in the wake of its withdrawal from UK markets, encapsulation in starch might just be the answer.

\section{Acknowledgements}

Analytical Services, Chemistry Department, Durham University, England is gratefully acknowledged. The corresponding author is grateful to the Association of Commonwealth Universities for scholarship that made this work possible.

\section{REFERENCES}

[1] J. O. D. Dailey, "Volatilization of Alachlor from Polymeric Formulations," Journal of Agricultural and Food Chemistry, Vol. 52, No. 22, 2004, pp. 6742-6746. doi:10.1021/jf040034g

[2] L. T. Zeoli, A. F. Kydonieus and A. F. Quisumbing, "Controlled Release Technologies," In: A. F. Kydonieus and M. Beroza, Eds., Insect Suppression with Controlled Release Pheromone Systems, CRC, Boca Raton, 1982, pp. 131-145.

[3] K. Tsuji, "Microencapsulation of Pesticides and Their Improved Handling Safety," Journal of Microencapsulation, Vol. 18, No. 2, 2001, pp. 137-147. doi:10.1080/026520401750063856

[4] T. Roberts, "Metabolic Pathways of Agrochemicals Part 1, Herbicides and Plant Growth Regulators," RSC, Cambridge, 1998, pp. 281-289. doi:10.1039/9781847551382

[5] USEPA, "Fact Sheet," 1996. http://www.epa.gov/oppsrrd1/REDs/factsheets/0179fact.p df

[6] L. R. Zimmerman, E. M. Thurman and K. C. Bastian, "Detection of Persistent Organic Pollutants in the Mississippi Delta Using Semi-Permeable Membrane Devices," Science of the Total Environment, Vol. 248, No. 2-3, 2000, pp. 169-179. doi:10.1016/S0048-9697(99)00540-9

[7] P. R. F. Barret, "Some Studies on the Use of Alginates for the Placement and Controlled Release of Diquat on Submerged Aquatic Plants," Pesticide Science, Vol. 9, No. 5, 1978, pp. 425-433. doi:10.1002/ps.2780090507

[8] W. J. Connick Jr., "Controlled Release of the Herbicides 2,4-D and Dichlobenil from Alginate Gels," Journal of Applied Polymer Science, Vol. 27, No. 6, 1982, pp. 33413348. doi:10.1002/app.1982.070270912

[9] L. Vollner, "Agrochemical Formulations for Improved Efficacy and Reduced Environmental Impacts: Slow Release Formulations with Natural Polymers," In: M. Mansour, Ed., Study and Prediction of Pesticides Behaviour in Soils, Plants and Aquatic Systems, GSF, Neuherberg, 1990, pp. 136-145.

[10] J. Gan, M. Hussain and M. N. Rathor, "Behaviour of Alginate Kaolin Based Controlled-Release Formulations of the Herbicide Thiobencarb in a Simulated Ecosystem,"
Pesticide Science, Vol. 42, No. 4, 1994, pp. 261-272. doi: $10.1002 /$ ps. 2780420403

[11] A. B. Pepperman and J. W. Kuan, "Slow Release Formulations of Metribuzin Based on Alginate-Kaolin-Linseed Oil," Journal of Controlled Release, Vol. 26, No. 1, 1993, 26, pp. 21-30. doi:10.1016/0168-3659(93)90205-J

[12] A. B. Pepperman and J. W. Kuan, "Controlled Release of Alachlor Based on Calcium Alginate," Journal of Controlled Release, Vol. 34, No. 1, 1995, pp. 17-23. doi:10.1016/0168-3659(94)00111-7

[13] M. Fernandez-Perez, M. Villa-Franca-Sanchez, E. Gonzalez-Pradas and F. Flores-Cespedes, "Controlled Release of Diuron from an Alginate-Bentonite Formulation: Water Release Kinetics and Soil Mobility Study," Journal of Agricultural and Food Chemistry, Vol. 47, No. 2, 1999, pp. 791-798. doi:10.1021/jf980878y

[14] F. Cespedes, M. Villa-Franca-Sanchez, S. Perez-Garcia and M. Fernandez-Perez, "Modifying Sorbents in Controlled Release Formulations to Prevent Herbicides Pollution," Chemosphere, Vol. 69, No. 5, 2007, pp. 785-794. doi:10.1016/j.chemosphere.2007.05.005

[15] B. Singh, D. K. Sharma, R. Kumar and A. Gupta, "Controlled Release of the Fungicide Thiram from StarchAlginate-Clay Based Formulation," Applied Clay Science, Vol. 45, No. 1-2, 2009, pp. 76-82. doi:10.1016/i.clay.2009.03.001

[16] D. Trimnell, B. S. Shasha and W. M. Doane, "Release of Trifluralin from Starch Xanthide Encapsulated Formulations," Journal of Agricultural and Food Chemistry, Vol. 29, No. 3, 1981, pp. 637-640. doi:10.1021/jf00105a050

[17] D. Trimnell and B. S. Shasha, "Entrapment of Herbicides in Starch for Spray Applications," Journal of Controlled Re-lease, Vol. 7, No. 3, 1988, pp. 263-268.

[18] M. G. Dosskey, D. C. Adriano, C. E. Murphy and J. C. Corey, "Effectiveness of a Slow Release Herbicide System for Control of Root Intrusions into Buried Hazardous Waste," Hazardous Waste and Hazardous Materials, Vol. 8, No. 4, 2009, pp. 293-301. doi:10.1089/hwm.1991.8.293

[19] W. J. Connick Jr., "Controlled Release of Bioactive Materials Using Alginate Gel Beads," US Patent 4401456, 1983.

[20] R. Celis, M. C. Hermosin, J. Carrizosa and J. Cornejo, "Inorganic and Organic Clays as Carriers for Controlled Release of the Herbicide Hexazinone," Journal of Agricultural and Food Chemistry, Vol. 50, No. 8, 2002, pp. 2324-2330. doi:10.1021/jf011360o

[21] L. A. Nnamonu, R. Sha'Ato and I. Onyido, “Adsorption Studies of Trifluralin on Kaolin," Nigerian Journal of Pure and Applied Science, Vol. 4, 2011, pp. 68-75.

[22] M. S. Mills and E. M. Thurman, "Reduction of Non-Point Source Contamination of Surface Water and Ground Water by Starch Encapsulation of Herbicides," Environmental Science \& Technology, Vol. 28, No. 1, 1994, pp. 73-79. doi:10.1021/es00050a011

[23] R. E. Wing, S. Maiti and W. M. Doane, "Amylose Content of Starch Controls the Release of Encapsulated Bioactive Agents," Journal of Controlled Release, Vol. 7, No. 
1, 1988, pp. 33-37. doi:10.1016/0168-3659(88)90077-6

[24] M. E. Carr, R. E. Wing and W. M. Doane, "Encapsulation of Atrazine within a Starch Matrix by Extrusion Processing," Cereal Chemistry, Vol. 68, No. 3, 1991, 68, pp. 262266.

[25] D. D. Buhler, W. C. Koskinen, M. M. Schreiber and J. Gan, "Dissipation of Alachlor, Metolachlor, and Atrazine from Starch-Encapsulated Formulations in a Sandy Loam Soil," Weed Science, Vol. 42, No. 3, 1994, pp. 411-417.

[26] Z. Gerstl, A. Nasser and U. Mingelgrin, "Controlled Release of Pesticides into Water from Clay-Polymer Formulations," Journal of Agricultural and Food Chemistry, Vol. 46, No. 9, 1998, pp. 3803-3809.

doi: $10.1021 / \mathrm{jf} 980184 \mathrm{p}$ 